complex," says Phillip Tarr, a microbiologist at Washington University in St Louis, Missouri. Tauxe concedes that more research is needed to better understand STEC pathology. "This is an area that we expect to evolve," he says. But if the meat-packing industry challenges the rule in court, as it has done for some previous USDA measures, the science of $E$. coli toxicity could soon find itself again under the microscope - this time, a legal one.

\title{
Reform falters after Europe's E. coli scare
}

\section{Political debate leaves German surveillance law in limbo.}

\section{BY MARIAN TURNER}

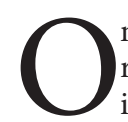
ne year on from Europe's worst recorded outbreak of Escherichia coli infection, governments have made little progress towards improving the monitoring and reporting systems that allowed the crisis to drag on for weeks. The disease, which was spread by contaminated fenugreek sprouts, swept across northern Germany in May and June 2011, infecting thousands and killing 53 people (see Nature 474, 137; 2011). Yet although the panic has sparked some proposed policy changes, these have become mired in political debate at both German and European levels.

Under Germany's current system, it can take up to 18 days for local and state health departments to relay case reports to the Berlinbased Robert Koch Institute (RKI), the German federal agency for disease surveillance. Legislators have proposed a law to bring the country's disease-reporting schedule into line with the World Health Organization's International Health Regulations. The law would require local health authorities to report cases of notifiable diseases to state authorities on the next working day; the states would then have another day to relay the information to the RKI. "We've been waiting almost a decade for this," says Alexander Kekulé, a microbiologist at the Martin Luther University of HalleWittenberg in Halle, Germany.

The draft law has been passed by Germany's federal parliament but is stuck in negotiations at the legislative council that represents Germany's 16 states. For scientists, though, this change would still not be enough. "What really delayed the detection of this outbreak was the irregularity with which patients were referred for microbiological follow-up," says Gérard Krause, an epidemiologist at the RKI. Like many European countries, Germany does not require that a patient with bloody diarrhoea or haemolytic uraemic syndrome (a life-threatening complication of some E. coli infections) be tested for the causative bacterial strain. The same is true of the United States.

After the outbreak, German diagnostic laboratories were provided with kits to test samples for genes belonging to certain pathogenic strains of bacteria, such as those expressing particular toxins, or proteins involved in adhesion or invasion. But physicians are responsible for requesting the tests, and the cost is not covered by German health-insurance companies. "The problem is mostly getting the money to use these kits," says Angelika Fruth, a microbiologist at the RKI, "and that situation is just the same as before the outbreak."

It is not only people who need to be tested the source of most human infection is contaminated food. In the wake of the outbreak, the European Food Safety Authority concluded that sprouted seeds pose a particular foodsafety concern (EFSA J. 9, 2424-2525; 2011), and recommended that a standardized test for sprouts be developed and adopted across the European Union (EU). But EU member countries are still discussing the proposal, and scientists have yet to develop reliable methods to isolate pathogenic bacteria from seeds or sprouts. Meat can also carry E. coli, but whereas the United States screens meat for disease-causing strains (see page 558), EU countries do not routinely do so, relying instead on farm and slaughterhouse hygiene.

There is room for optimism, however. Flemming Scheutz, head of the World Health Organization Collaborative Centre for Reference and Research on Escherichia and Klebsiella in Copenhagen, believes that after last year's outbreak, physicians are at least more likely to recognize and report food-borne infections. The crisis also coincided with the advent of inexpensive whole-genome sequencing technology, resulting in a glut of new bacterial sequences. Genomics and public-health research groups are now studying how these might help to tackle future outbreaks.

"The push for novelty among testing and surveillance systems will come from scientists rather than politics," says Scheutz. - 